\title{
PERAMALAN JUMLAH PERMINTAAN UDANG BEKU PND MENGGUNAKAN METODE JARINGAN SYARAF TIRUAN (JST) BACKPROPAGATION
}

\author{
Forecasting of PND Frozen Shrimp Demand Using
}

Artificial Neural Network Method (ANN) Backpropagation

\author{
Iid Mufaidah ${ }^{1) *}$, Sony Suwasono ${ }^{2)}$, Yuli Wibowo ${ }^{3)}$, Deddy Wirawan Soedibyo ${ }^{4)}$ \\ ${ }^{1)}$ Magister Teknologi Agroindustri, Fakultas Teknologi Pertanian, Universitas Jember \\ ${ }^{2)}$ Jurusan Teknologi Hasil Pertanian, Fakultas Teknologi Pertanian, Universitas Jember \\ ${ }^{3)}$ Prodi Teknologi Industri Pertanian, Fakultas Teknologi Pertanian, Universitas Jember \\ ${ }^{4)}$ Teknik Pertanian, Fakultas Teknologi Pertanian, Universitas Jember \\ Jalan Kalimantan No. 37 Jember, 68121 \\ *E-mail: iid_mufaidah@yahoo.com
}

\begin{abstract}
Forecasting is the art or science to estimate how many needs will come in order to meet the demand for goods or services, often based on historical time series data. The growing number of emerging companies in Indonesia today has created a very tight business competition in both services and products. Consumers choose the best service and high quality and low price. Consumer demand is always uncertain or varied in each subsequent period. The aim of this research was to determind the best backpropagation neural network architecture design and to predict the demand of frozen product of PND 26/30. This research used the method of Neural Network (ANN) and Processing ANN using MATLAB software. Implementation of ANN method in PT.XYZ using Backpropagation algorithm. Artificial neural network architecture used was 12 input layer, 1 output layer, and 12 hidden layer and activation function used tansig and purelin. Tansig for hidden layer and purelin for output layer. The best artificial neural network architecture design for product demand for PND 31/40 was a multi layer feedforward value of Mean Square Error (MSE) network training value of 0.01 with MAPE 3.35. The result of JST forecasting period 2017 were 960 MC, 637 MC, 572 MC, 993 MC, 1386 MC, 480 MC, 135 MC, 1209 MC, 1476 MC, 1029 MC, 290 MC, and $952 M C$.
\end{abstract}

Keywords: artificial neural network, PND 26/30, backpropagation, MSE, MAPE

\section{PENDAHULUAN}

PT. XYZ Banyuwangi merupakan perusahaan yang bergerak sebagai industri vanamei (udang) untuk kebutuhan ekspor dalam bentuk frozen. Peluang pasar dan perkembangan agroindustri ini menyebabkan persaingan perusahaan semakin besar dalam memperebutkan konsumen. Hal tersebut juga mengakibatkan meningkatnya tuntutan konsumen terhadap kualitas dan kuantitas (ketersediaan) dari suatu produk di gudang.

Persediaan barang atau produk merupakan salah satu aspek perusahaan yang memiliki peranan penting dalam operasi bisnis dengan manajemen yang proaktif. Oleh karena itu perusahaan harus mampu mengantisipasi keadaan maupun tantangan yang ada di dalam manajemen persediaan untuk mencapai sasaran akhir yaitu untuk meminimalisasi biaya yang dikeluarkan untuk persediaan (Yamit, 2002). Dalam sistem industri, adanya persediaaan merupakan faktor pemicu meningkatnya biaya. Penetapan jumlah persediaan terlalu banyak akan berakibat pemborosan dalam biaya simpan, akan tetapi apabila terlalu sedikit maka akan mengakibatkan hilangnya kesempatan perusahaan untuk mendapatkan keuntungan jika permintaan barangnya lebih besar dari jumlah persediaaan yang di gudang.

Maka untuk mengatasi kendala dalam memenuhi kebutuhan ekspor dan 
memperlancar ketersediaan produk jadi udang (vanamei) beku di PT. XYZ Banyuwangi maka dibutuhkan peramalan permintaan produk. Peramalan permintaan yang digunakan adalah peramalan dengan menggunakan jaringan syaraf tiruan. Jaringan syaraf tiruan (artificial neural network) atau disingkat dengan JST adalah sistem komputasi dimana arsitektur dan operasi diilhami dari pengetahuan tentang sel biologi dalam otak manusia (Kristanto, 2004). Jaringan syaraf merupakan salah satu satu representasi buatan dari otak manusia yang mensimulasikan proses pembelajaran pada otak manusia tersebut. Istilah buatan disini digunakan karena jaringan saraf ini diimplementasikan dengan menggunakan program komputer yang mampu menyelesaikan sejumlah proses perhitungan selama proses pembelajaran (Hecht-Nielsend 1988; Kusumadewi, 2004).

JST yang digunakan dalam penelitian ini adalah backpropagation yang merupakan salah satu metode yang sangat baik dalam menangani masalah pengenalan pola-pola kompleks. Di dalam jaringan propagasi balik setiap unit yang berada di lapisan input terhubung dengan setiap unit yang ada di hidden layer. Setiap unit yang ada di hidden layer terhubung setiap unit yang ada di lapisan output. Jaringan ini terdiri dari banyak lapisan (multi layer network). Ketika jaringan diberikan pola masukan sebagai pola pelatihan, maka pola tersebut menuju unitunit hidden layer untuk selanjutnya diteruskan pada unit-unit di lapisan keluaran. Kemudian pada lapisan keluaran kaan memberikan respon sebagai keluaaraan JST. Saat hasil keluaran tidak sesuai dengan yang diharapkan, maka keluaran aakan disebarkan mundur (backward) pada hidden layer kemudian menuju lapisan masukan (Puspitaningrum, 2006).

Pada penelitian sebelumnya, menurut Imam et al. (2007) JST berguna untuk meramalkan permintaan komoditas karet yang dipengaruhi oleh stok dan harga produk. Penelitian Hariati (2012), volume penjualan dan harga merupakan faktor yang mempengaruhi permintaan produk tempe. Pada penelitian Sabati (2014), Peramalan Permintaan sari apel dengan metode Jaringan syaraf tiruan (JST) di KSU Brosem, Batu. Pada penelitian ini JST (jaringan syaraf tiruan) digunakan untuk meramalkan permintaan udang beku PND 26/30 di PT. XYZ Banyuwangi.

\section{METODE PENELITIAN}

Data yang dikumpulkan adalah berupa data sekunder yaitu data volume penjualan periode Januari 2010-Desember 2016. Variabel penelitian ini adalah data input yaitu volume penjualan tahun sebelumnya dan output berupa prediksi permintaan produk. Pola yang terbentuk terdiri dari 57 pola terdiri dari 43 pola untuk pelatihan dan 14 pola digunakan untuk simulasi dengan alur JST sebagai berikut:

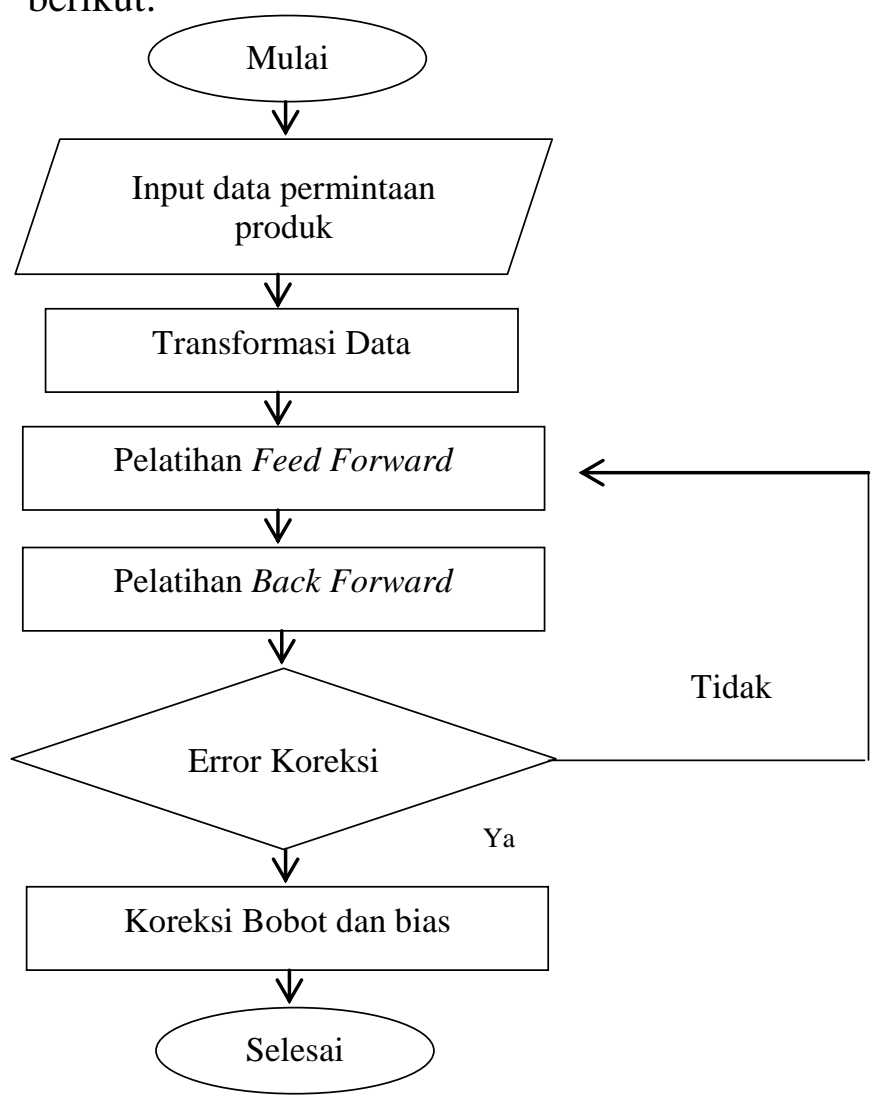

Gambar 1. Alur jaringan syaraf tiruan 


\section{Persiapan Data Masukan}

Data yang menjadi masukan dalam pelatihan adalah seluruh data training (Januari 2010 sampai Desember 2016), dimana $75 \%$ untuk training dan $25 \%$ sisanya untuk testing. Data training digunakan untuk membentuk data model dan data testing digunakan untuk menguji ketepatan klasifikasi dari model yang telah dibentuk (Aprijani, 2011).

\section{Preprocessing (Transformasi data)}

Data input dan target ini kemudian dinormalisasi atau disebut dengan penskalaan data (Siang, 2009):

$$
\mathrm{X}^{\prime}=\frac{0.8(x-a)}{b-a}+0.1
$$

Keterangan:

$\mathrm{X}^{\prime}=$ transformasi linear menjadi interval $(0,1: 0,9)$

$x=$ data yang diakan diramal

$a$ = data minimum

$b$ = data maksimum.

\section{Pelatihan (Training) Backpropagation}

Proses training pada jaringan syaraf tiruan backpropagation adalah prosedur untyuk melakukan pembelajaran terhadap pola yang dikenali. Model jaringan syaraf tiruan yang diterapkan adalah dengan beberapa lapis hidden layer. Multi layer perceptron merupakan jaringan yang memiliki banyak lapis. Fungsi aktivasi yang digunakan yaitu tansig dan purelin. (Siang, 2009).

Hasil syntax yang digunakan untuk menampilkan perintah-perintah tersebut yaitu:

\footnotetext{
$>$ net=newff (minmax (i), $[12,1],\{$ 'tan sig', 'purelin'\}, 'traingdm');

$>$ net.trainParam.goal=0.01;

$>$ net.trainParam. epochs $=5000$;

$>$ net=train (net, $i, t)$;
}

Keterangan:

net $=$ model jaringan syaraf yang terpilih $i \quad=$ matriks inputan jaringan syaraf yang sudah

$t=$ merupakan matriks target jaringan syaraf

Inisialisasi bobot awal dengan intruksi sebagai berikut:

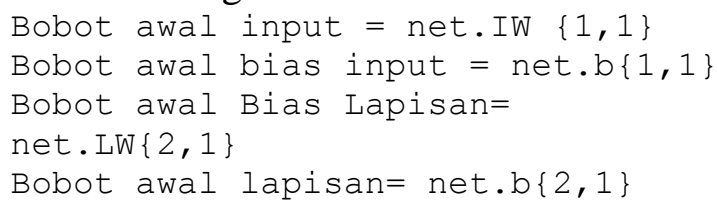

Pada tahapan ini dilihat dari arsitektur jaringan terdapat 12 hidden layer. Selanjutnya akan diketahui menghasilkan performansi terbaik berdasarkan nilai fungsi kinerja jaringan dalam mean square error (MSE) yang telah ditentukan, maka neuron jaringan yang terbaiklah yang akan digunakan pada saat training berlangsung.

\section{Postprocessing}

Jaringan perlu diberikan proses simulasi terlebih dahulu. Syntax yang dimasukkan untuk proses simulasi adalah:

$$
\mathrm{z}=\operatorname{sim}(\text { net, } i)
$$

Keterangan:

$$
\begin{aligned}
\text { an }= & \text { output jaringan syaraf } \\
\text { net }= & \text { model jaringan syaraf yang telah } \\
& \text { terpilih } \\
i \quad= & \text { matriks inputan jaringan syaraf } \\
& \text { Bila dalam preprocessing }
\end{aligned}
$$
perintah dalam menormalisai, maka dalam denormalisasi pada postprocessing dengan menggunakan rumus sebagai berikut:

$$
\mathrm{X}=\frac{\left(x^{I}-0,1\right)(b-a)}{0,8}+\mathrm{a}
$$

Keterangan:

$$
\begin{aligned}
& \mathrm{X}=\text { data denormalisasi } \\
& x=\text { data hasil normalisasi } \\
& a=\text { data minimum } \\
& b=\text { data maksimum. }
\end{aligned}
$$




\section{HASIL DAN PEMBAHASAN}

Berdasarkan data historis volume penjualan pada periode Januari 2010samapai dengan Desember 2016 maka dapat diketahui bahwa hasil penjualan tujuh tahun terakhir untuk produk PND 26/30 adalah fluktuatif dengan pola musiman. Hanya saja pada tahun 2016 permintaan pasar berjumlah tetap untuk setiap bulannya. Maka untuk mempermudah peramalan tahun 2017 dengan jalan membangkitkan data tahun 2016 terlebih dahulu. Berikut Gambar ploting permintaan produk PND 26/30 tujuh tahun terakhir.
Tabel 1. Data permintaan PND26/30

\begin{tabular}{lccccccc}
\hline Tahun & 2010 & 2011 & 2012 & 2013 & 2014 & 2015 & 2016 \\
\hline Januari & 350 & 400 & 450 & 550 & 500 & 550 & 3150 \\
Februari & 700 & 800 & 900 & 1050 & 1000 & 1050 & 3150 \\
Maret & 500 & 650 & 700 & 850 & 800 & 900 & 3150 \\
April & 1150 & 1300 & 1400 & 1700 & 1600 & 1700 & 3150 \\
Mei & 550 & 600 & 650 & 800 & 750 & 850 & 3150 \\
Juni & 500 & 600 & 600 & 750 & 700 & 800 & 3150 \\
Juli & 600 & 650 & 700 & 850 & 800 & 900 & 3150 \\
Agustus & 700 & 800 & 900 & 1050 & 1000 & 1050 & 3150 \\
September & 850 & 1000 & 1050 & 1300 & 1200 & 1300 & 3150 \\
Oktober & 700 & 800 & 900 & 1050 & 1000 & 1050 & 3150 \\
November & 350 & 400 & 450 & 550 & 500 & 550 & 7550 \\
Desember & 350 & 400 & 450 & 550 & 500 & 550 & 7250 \\
\hline
\end{tabular}

PND 26/30

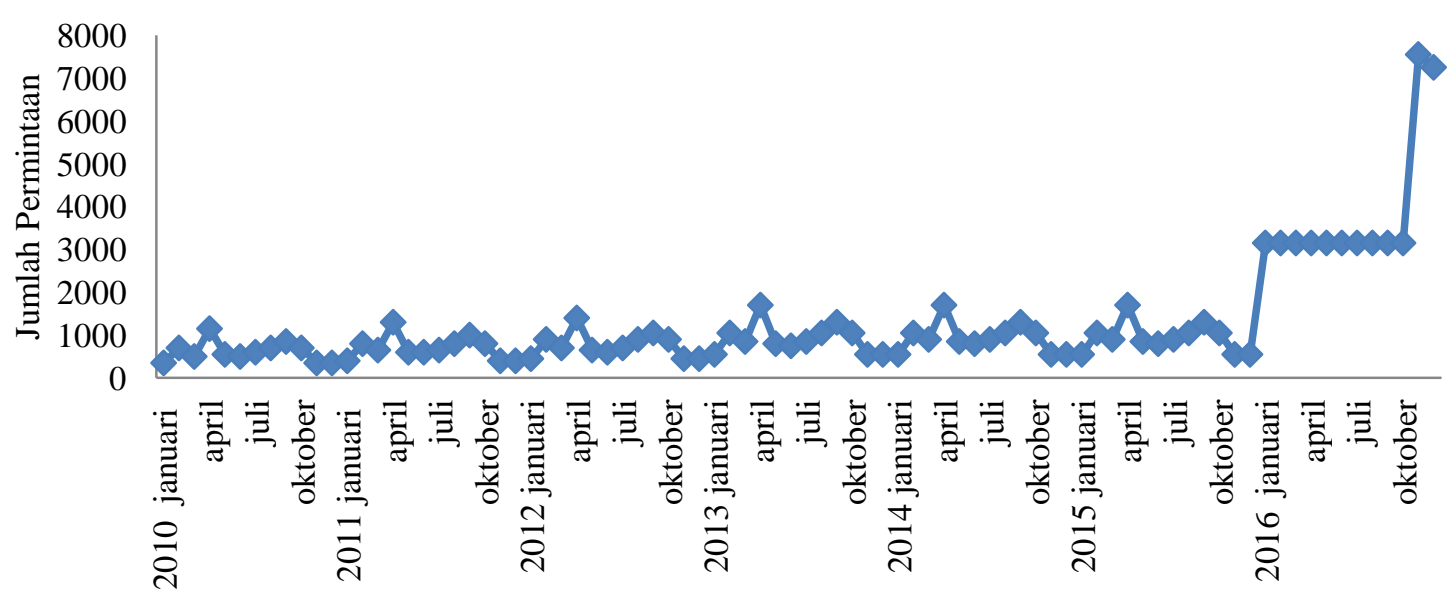

Gambar 2. Ploting permintaan PND 26/30 tahun 2010-2016 
Permintaan pasar tujuh tahun terkhir kemudian dilakukan training dengan arsitektur jaringan yang telah ditentukan adalah 12 data input dan 12 hidden layer menghasilkan satu output. Dimana periode satu tahun untuk memprediksi bulan ke empat pada tahun berikutnya karena dengan pertimbangan manajemen bahwa pengumpulan bahan baku dilakukan selama 4 bulan dengan arsitektur sebagai berikut:

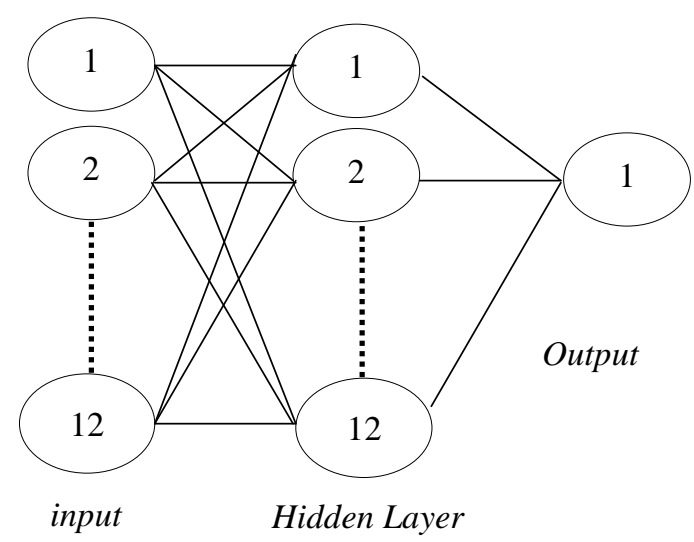

Gambar 3. Arsitektur jaringan syaraf tiruan

Berdasarkan arsitektur jaringan yang terpilih, data historis dilatih dengan fungsi aktivasi tansig purelin. Grafik pelatihan memiliki performansi konvergensi setelah mencapai iterasi 849 epoch hasil pelatihan sudah menghasilkan sebesar MSE 0,01. Gambar 4 merupakan grafik hasil pelatihan dari data historis.

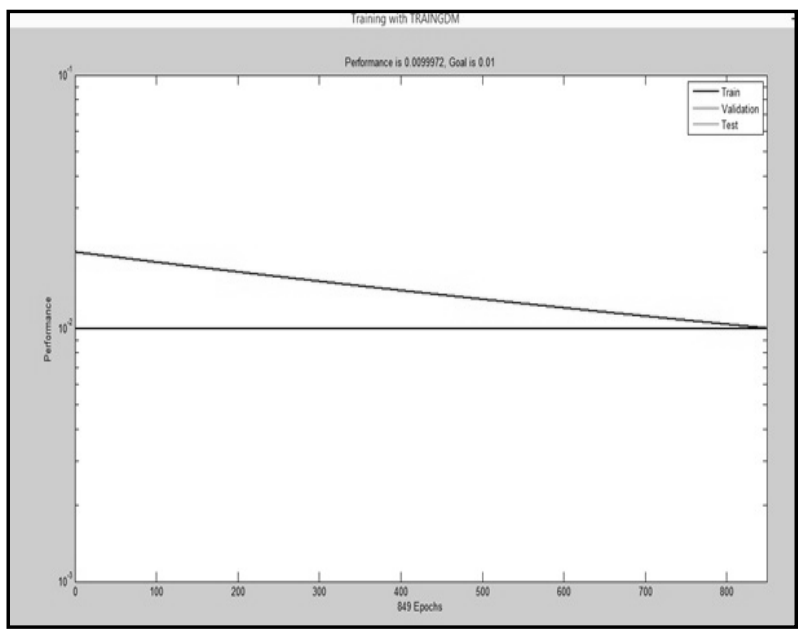

Gambar 4. Grafik pelatihan JST

Proses pelatihan yang dilakukan selanjutnya pola yang tersisa digunakan untuk simulasi atau data testing untuk mengetahui perbandingan antara hasil simulasi dengan target. Data simulasi dapat dilihat pada Tabel 2.

Tabel 2. Perbandingan nilai target dan simulasi

\begin{tabular}{ccccc}
\hline \multicolumn{2}{c}{ Normalisasi } & \multicolumn{2}{c}{ Denormalisasi } & \% \\
Target & $\mathbf{Z}$ & Target & $\mathbf{Z}$ & \\
\hline 0,485185 & 0,439431 & 1.000 & 923 & 7,70 \\
0,188889 & 0,355227 & 500 & 781 & $-56,20$ \\
0,188889 & 0,086004 & 500 & 326 & 34,80 \\
0,218519 & 0,306694 & 550 & 699 & $-27,09$ \\
0,514815 & 0,381558 & 1.050 & 825 & 21,43 \\
0,425926 & 0,278155 & 900 & 651 & 27,67 \\
0,9 & 0,719591 & 1.700 & 1396 & 17,88 \\
0,396296 & 0,419107 & 850 & 888 & $-4,47$ \\
0,366667 & 0,333115 & 800 & 743 & 7,13 \\
0,425926 & 0,248621 & 900 & 601 & 33,22 \\
0,514815 & 0,631965 & 1.050 & 1.248 & $-18,86$ \\
0,662963 & 0,592276 & 1.300 & 1.181 & 9,15 \\
0,514815 & 0,41753 & 1.050 & 886 & 15,62 \\
0,218519 & 0,372879 & 550 & 810 & $-47,27$ \\
0,218519 & 0,112541 & 550 & 371 & 32,55 \\
\hline MAPE & & & & 3,55 \\
\hline Jumlah & & 13.250 & 12.329 & 6,95 \\
\hline
\end{tabular}


Setelah pelatihan dan pengujian data, maka dilakukan peramalan dengan JST terbaik, sehingga diperoleh prediksi jumlah permintaan PND 26/30 tahun 2017. Peramalan JST PNG 26/30 tahun 2017 dapat dilihat pada Tabel 3.

Tabel 3. Peramalan JST PND 26/30 tahun 2017

\begin{tabular}{ccc}
\hline Periode 2017 & $\begin{array}{l}\text { Hasil JST } \\
2017\end{array}$ & $\begin{array}{l}\text { Peramalan JST } \\
\text { (MC) }\end{array}$ \\
\hline Januari & 0,4614 & 960 \\
Februari & 0,2703 & 637 \\
Maret & 0,2318 & 572 \\
April & 0,4809 & 993 \\
Mei & 0,7137 & 1386 \\
Juni & 0,1771 & 480 \\
Juli & $-0,0274$ & 135 \\
Agustus & 0,6089 & 1209 \\
September & 0,7674 & 1476 \\
Oktober & 0,5026 & 1029 \\
November & 0,0642 & 290 \\
Desember & 0,4567 & 952 \\
\hline
\end{tabular}

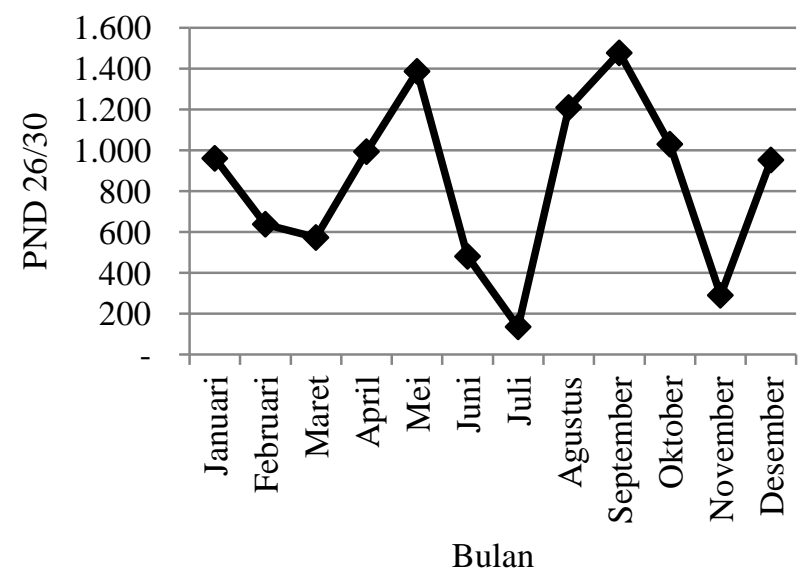

Gambar 5. Grafik peramalan PND 26/30 tahun 2017

\section{KESIMPULAN}

Arsitektur Jaringan syaraf tiruan yang dapat digunakan untuk peramalan permintaan PND $26 / 30$ di PT. XYZ Banyuwangi adalah jaringan adalah jaringan syaraf tiruan backpropagation dengan nilai Mean Square Error (MSE) 0,01 dan nilai MAPE pengujian data sebesar 3,35. Hasil Peramalan Jaringan syaraf tiruan periode 2017 PND 26/30 yaitu $960 \mathrm{MC}, 637 \mathrm{MC}, 572 \mathrm{MC}, 993$ MC, 1386 MC, 480 MC, 135 MC, 1209 MC, 1476 MC, 1029 MC, 290 MC, dan $952 \mathrm{MC}$.

\section{UCAPAN TERIMAKASIH}

Ucapan terimakasih ditujukan kepada Ketua Asosiasi Shrimp Club Banyuwangi yang telah memberikan informasi dan dukungannya.

\section{DAFTAR PUSTAKA}

Aprijani, D. 2011. Aplikasi jaringan syaraf tiruan untuk mengenali tulisan tangan huruf A, B, C dan D pada jawaban soal pilihan ganda. Jurnal Matematika, Sains dan Teknologi, 12 (1): 11-17.

Hariati, I.P., Deoranto, P., dan Dewi I.A. 2012. Peramalan permintaan produk keripik tempe CV. Aneka Rasa dengan metode jaringan syaraf tiruan. Jurnal Teknik Industri, 1 (1): 10-21.

Hecth-Nielsend. 1988. Application of Counterpropagation Network, Neural Network. IEE Press, New York.

Imam, S., Effendi, U., dan Fauziya, C. 2007. Penerapan jaringan syaraf tiruan untuk peramalan permintaan komoditas karet di PT. Perkebunan Nusantara XII Surabaya. Jurnal Teknologi Pertanian, 8 (1): 46-54.

Kristanto, A. 2004. Jaringan Syaraf Tiruan (Konsep Dasar, Algoritma dan Aplikasi). Gava Media, Yogyakarta.

Kusumadewi, S. 2004. Membangun Jaringan Syaraf Tiruan, Menggunakan Matlab dan Excel Link. Graha Ilmu, Yogyakarta.

Puspitaningrum, D. 2006. Pengantar Jaringan Syaraf Tiruan. Penerbit Andi, Jogjakarta. 